\title{
CONTEXTOS MORTUORIOS EN LA REGIÓN DEL CANAL BEAGLE... DEL HALLAZGO FORTUITO A LA BÚSQUEDA SISTEMÁTICA
}

\author{
ERNESTO PIANA*, AUGUSTO TESSONE** Y A. FRANCISCO ZANGRANDO***
}

\begin{abstract}
RESUMEN
En este trabajo presentamos los resultados obtenidos de tareas de prospección y excavación de contextos mortuorios humanos efectuadas en la costa norte del canal B eagle (Tierra del Fuego, Argentina). Se describen los procedimientos metodológicos empleados en dichas actividades, los cuales son asimismo analizados a la luz de los procesos naturales y culturales que intervinieron en la formación de dicho registro. Finalmente, sobre la base de la información existente en la bibliografía y la aquí presentada, desarrollamos una serie de observaciones iniciales sobre las prácticas asociadas a la muerte y los modos de disposición de restos humanos en el archipiélago fueguino.
\end{abstract}

PALABRAS CLAVES: restos humanos, conductas mortuorias, archipiélago fueguino.

MORTUARY CONTEXTS IN THE BEAGLE CHANNEL REGION... FROM THE OCCASIONAL FINDING TO THE SYSTEMATIC SURVEY

\begin{abstract}
This paper presents the results of surveys and excavations of human mortuary contexts made in the north coast of the Beagle Channel (Tierra del Fuego, Argentina). Methodological procedures are delineated and analyzed to address both natural and cultural processes that have affected the formation of the mortuary record. We conclude by offering a few initial observations on activities related to death and burial patterns in the Fuegian archipelago.
\end{abstract}

KEY WORDS: human remains, mortuary behaviors, fuegian archipelago.

* CONICET - CADIC - Bernardo Houssay 200 (V9410CAB) Ushuaia. Tierra del Fuego, Argentina. E-mail: arqueologia@ cadic.gov.ar

** CONICET-UBA-INGEIS - Pabellón INGEIS, Ciudad Universitaria (CP1428), Buenos Aires, Argentina. E- mail: gutitessone@yahoo.com.ar

*** CONICET - AIA / UBA - Rivadavia 137911 «»(CP1033), Buenos Aires, Argentina. E-mail: panchozan@ yahoo.com.ar 


\section{INTRODUCCIÓN}

Dentro del marco general del Proyecto Arqueológico Canal Beagle (Orquera y Piana 1999a), se ha comenzado una línea de investigación cuyo objetivo es estudiar las conductas mortuorias en esta región ${ }^{1}$. Un examen crítico de los antecedentes arqueoló gicos refleja claramente la escasez de conocimiento e información sobre el tema. En efecto, la mayoría de los restos óseos humanos conocidos provienen de hallazgos fortuitos y muy pocos cuentan con información contextual y cronológica (Aspillaga et al. 1999; Guichón 2000; Van de Maele 2000; Tessone 2003). Como paso inicial en estas investigaciones desarrollamos una búsqueda sistemática de restos óseos humanos y la exploración de diversos factores que inciden sobre la distribución, visibilidad y preservación del registro bioarqueológico ${ }^{2}$ en la región del canal Beagle. En el 2001 se realizó una prospección puntual y preparatoria. Posteriormente, entre 2002 y 2004 se desarrollaron prospecciones intensivas y sistemáticas. Aquí se informan los resultados alcanzados en dichas tareas.

Naturalmente, las conductas mortuorias constituyen uno de los factores más influyentes sobre la configuración del registro biológico humano (Dillehay 1997; Barrientos 2002, entre otros). En este sentido existe acuerdo en que se debe explorar la distribución espacial de los contextos y la forma de disposición de los cuerpos desde una perspectiva regional para discutir la existencia de patrones mortuorios. Pero también es necesario analizar bajo la misma perspectiva espacial qué variables depositacionales y postdepositacionales influyen en la formación de este registro y cuáles inciden puntualmente en la capacidad de su detección (Guichón et al. 2000; Guichón et al. 2001; Zangrando et al. 2004; Martin 2004; Barrientos et al. 2006). Se discute asimismo el sesgo emergente de los propios límites de la prospección arqueológica, para lo cual

1 Parte del Proyecto «Variabilidad de los procesos de producción y reproducción social en los canales magallánicos-fueguinos (PIP CONICET 6186)».

2 Si bien el término «bioarqueología» es empleado en la bibliografía para hacer referencia a los estudios efectuados a partir de restos humanos y/o faunísticos, en este trabajo adoptamos ese término para aducir en forma exclusiva a restos humanos en contextos arqueológicos (sensu Larsen 1997). se evalúan los resultados obtenidos mediante dos estrategias implementadas en nuestras prospecciones.

En suma, en este trabajo desarrollamos un diagnóstico sobre la visibilidad, los procesos postdepositacionales, las estrategias de prospección utilizadas, los resultados que éstas alcanzaron y el estado actual del conocimiento acerca del registro bioarqueológico en la región del canal Beagle.

\section{CONTEXTOS MORTUORIOS: ACTUALIZACIÓN Y ANTECEDENTES}

El universo total de restos óseos humanos procedentes de la región del canal Beagle e inmediaciones presentados en trabajos científicos es de más de un centenar de individuos (Legoupil 1993-94; Orquera y Piana 1996; Pérez-Pérez 1996; Aspillaga et al. 1999; Guichón 2000; Guichón et al. 2001; Tessone 2003), pero sólo para una proporción muy reducida de ellos se conoce el contexto arqueológico y modo de inhumación, incluso en algunos parcialmente.

$\mathrm{H}$ yades (1885) en 1882 y Gusinde (1937:164) en 1919 excavaron en la región enterratorios muy recientes, pero sus objetivos eran etnográficos y antropológico-físicos. Las excavaciones de enterratorios de índole arqueológica comenzaron con Spencer (1951) en 1929, quien recuperó un esqueleto de un conchal, y con Bird (com.pers.) en 1935, quien rescató un esqueleto parcialmente conservado en un abrigo rocoso y fechó madera asociada en $970 \pm 90$ años ${ }^{14} \mathrm{C} A \mathrm{P}^{3}(\mathrm{I}-3989)^{4}$. Sin embargo, estas últimas no alcanzaron a ser publicadas. Salvo el esqueleto y un cráneo obtenidos por Gusinde en Ea Harberton, todos estos trabajos fueron realizados en la isla Navarino o islotes contiguos.

La siguiente publicación fue obra de Sánchez Albornoz (1958), quien describió un contexto mortuorio en Isla Redonda, frente a la bahía Ensenada. Los restos óseos humanos allí recuperados fueron dos cráneos y algunos elementos del esqueleto post-craneal, los cuales se

3 Todas las antigüedades mencionadas en este trabajo son años 14C AP no calibrados.

4 Código de Laboratorio del American Museum of Natural $\mathrm{H}$ istory. Muestra 1968-8. En ese momento se estimó una vida media de $5568 \pm 30$ años para el 14 C por lo que la fecha resulta algo envejecida si se la compara con análisis más recientes. 
encontraban depositados entre rocas (lajas) "en un punto escarpado a buena distancia del mar" (Sánchez Albornoz 1958: 9). Marcelo Bórmida determinó que los restos pertenecían a dos individuos infantiles. Debido a que el contexto mortuorio estaba parcialmente deteriorado en el momento del hallazgo, se desconoce la posición en la que estaban dispuestos los esqueletos (ibidem). La apreciación sobre la distancia al mar realizada por Sánchez Albornoz se considera relativa, dado que la isla en cuestión tiene un largo y un ancho máximos de 850 m y 650 m respectivamente.

En la década de 1970, Omar OrtizTroncoso excavó un esqueleto en el seno Lauta, en la costa norte de la isla Navarino. Los restos óseos pertenecían a un individuo femenino adulto, de 35-40 años de edad (Aspillaga et al. 1999: 129).

En 1985 y 1986 se hallaron restos pertenecientes a dos párvulos en dos sitios (I y X) de la localidad arqueológica Shamakush; en ambos casos los huesos estaban simplemente cubiertos por sedimentos del conchal. La edad del párvulo de Shamakush I se estimó en un rango de 0 a 6 meses. Los fechados radiocarbónicos fueron efectuados sobre carbón procedente de los depósitos en los cuales se encontraban los restos humanos, estableciéndose una edad máxima de $500 \pm 100$ ${ }^{14} \mathrm{C}$ AP para la capa $E$ de Shamakush $X$ y de $940 \pm 100{ }^{14} \mathrm{C}$ AP para la capa D de Shamakush I (Orquera y Piana 1996).

Legoupil (1993-94) efectuó hallazgos de restos óseos humanos en concheros de las islas Wollaston y Bayly, en el archipiélago del Cabo de Hornos. En Wollaston recuperó un húmero, tres vértebras y algunas costillas de un individuo adulto, que según esta investigadora se encontraba in situ en posición dorsal. En la isla Bayly recuperó un fragmento de cúbito y una vértebra en un sector erosionado de un conchero de grandes dimensiones (Bayly 1). La capa basal de este sitio fue fechada en $1410 \pm 50{ }^{14} \mathrm{C}$ AP (ibidem), lo que proporciona la antigüedad máxima posible para este individuo.

Un individuo masculino de edad senil (Kozameh y Testa 2004) fue recuperado en $1997^{5}$

5 Excavación realizada como parte del proyecto de la Unión Europea. CI1*-CT93-0015. Marine Resources Prior to Industrial Exploitation: an archaeological evaluation. Directores Dra. A. Vila, Lic. E. Piana y Dr. J . Estévez. en el casco de la Estancia Harberton. Se trata de un entierro primario colocado en posición decúbito lateral en una fosa de silueta irregular, excavada en una estructura de conchero preexistente. No existe asociación entre el entierro y el proceso de formación del conchal pues las paredes de la fosa seccionan la superposición de subunidades estratigráficas. Una cronología de $650 \pm 100$ años ${ }^{14} \mathrm{C}$ AP (AC 1370) fue obtenida de las subunidades superiores del depósito. El esqueleto se encontraba asociado a una lasca de vidrio, casi en contacto con la 4ta. vértebra lumbar, y a dos raspadores tallados sobre el mismo material casi en contacto con el cúbito izquierdo. Sus condiciones de preservación indican filos muy frescos, sin microrrastros de uso ni de fricción con sedimento (determinación de la Dra. Myrian Álvarez). Con respecto a la antigüedad máxima posible de esta inhumación, la asociación con los raspadores de vidrio indicaría un momento postcontacto con los europeos.

Durante la excavación del sitio Ajej I en 1999 (Piana et al. 2002), en Bahía Golondrina (dentro del ejido urbano de Ushuaia), se recuperó la mayor parte de un neonato. El análisis de edad del individuo no fue concluyente, pero se estimó en no mayor a 6 meses. La ausencia de ciertas porciones esqueletarías se adjudicó a una perturbación postdepositacional reciente y no a la depositación o deterioro diferencial de partes del cuerpo durante la formación del sitio. En el momento del hallazgo los restos no se encontraban en posición primaria, pero estaban estratigráficamente asociados en una dispersión inferior a un metro cuadrado. La capa que los contenía fue fechada en $1400 \pm 90$ años radiocarbónicos $A P$.

En el 2000 el equipo de investigación codirigido por Carlos O campo y Pilar Rivas recuperaron cuatro individuos en el Sitio 130, una estructura de conchero ubicada en la ensenada Villarino, en la costa norte de la isla Navarino (Ocampo et al. 2001). Los restos humanos fueron localizados a unos 200 metros de la costa y entre 18 y 20 msnm. La edad del individuo 1 se estimó en alrededor de 5 años. Este individuo estaba en posición fetal decúbito lateral derecho dentro de una pequeña fosa elíptica en el conchal, que fue en parte perturbada por acción de un arado. Un punzón o lezna de hueso y un conjunto de lascas asociadas al esqueleto fueron interpretadas como parte de un ajuar. Del carbón asociado a los restos óseos humanos se obtuvo una 
cronología de 490 30 AP (Ocampo et al. 2001).

La edad estimada para el individuo 2 es de 35 años o mayor. De este último se recuperó parte del tórax in situ, lo que permitió deducir que la posición original del cuerpo era decúbito lateral derecho. El individuo 3, de unos 10 años de edad, había sido recuperado en 1999 por Van de Maele en posición in situ en una excavación inmediata a la perturbación provocada por la instalación de una huerta. La excavación del espacio adyacente sugiere a los autores un patrón de inhumación similar al individuo 1. Del cuarto individuo, de entre 5 y 6 años de edad, sólo se recuperaron por cribado de material removido una tibia, dos fíbulas y fragmentos óseos no identificados.

Tareas de remodelación efectuadas en el predio del Aeroclub de Ushuaia expusieron los restos de un individuo adulto, del cual se recuperaron el cráneo, parte de los miembros superiores, parte de la columna cervical y torácica, esternón y costillas, faltando casi toda la mitad inferior. Ubicado a los 54운 48,91" S y 680 18' 20,18 " O, fue excavado e informado por las Dras. Salemme y Mansur (2002). Si bien parte de los sedimentos superiores habían sido eliminados y parte de esqueleto perdido, los elementos óseos recuperados estaban in situ, sin asociación con otro tipo de material arqueológico y no relacionados a conchero (Salemme y Mansur 2002).

Existe una serie de nueve hallazgos no comunicados previamente que se efectuaron durante el desarrollo del Proyecto Arqueológico Canal Beagle o debido a la intervención de parte del equipo ante la aparición y remoción de restos óseos humanos. Entre estos hallazgos se pueden destacar los restos recuperados de un individuo adulto (54은 $53,02^{\prime}$ S y $67039,22^{\prime}$ O, sobre el trazado de la ruta provincial № 30) durante el emplazamiento de una huerta en 1996 que removió un conchero relativamente extenso; los restos óseos estaban acumulados sobre material removido de conchero (Piana 1996). En los roquedales de Escarpado $\left(54^{\circ} 49,14^{\prime}\right.$ S y $68^{\circ} 10,81^{\prime}$ O) fueron localizados un cráneo, una mandíbula y la mitad proximal de un fémur derecho, todos con avanzado grado de meteorización; estaban dentro de una oquedad formada por grandes rocas caídas sin cobertura alguna. El resto de los casos corresponden a huesos aislados.

El Museo del Fin del Mundo (Ushuaia) cuenta asimismo con otros restos humanos provenientes de hallazgos fortuitos y con distinto gra- do de información sobre el lugar de procedencia o condiciones de hallazgo. La recopilación del estado del conocimiento sobre los antecedentes arqueológicos condujo a que, en los casos que la información lo permitía, se revisaran las áreas donde habían ocurrido esos hallazgos; así se pudieron determinar rangos máximos y mínimos de altura sobre nivel del mar y de distancias a costa y/o datos ambientales.

\section{METODOLOGÍA Y CONDICIONES PARA LA} BÚSQUEDA DE RESTOS ÓSEOS HUMANOS

Se decidió articular la búsqueda de contextos mortuorios a partir de dos métodos distintos. Uno de ellos, que definimos como estrategia dirigida, estuvo destinado a prospectar emplazamientos con las características similares a la información de base antes resumida y a la proporcionada por fuentes históricas, esta última recopilada por Orquera y Piana (1999b). Con el fin de disminuir potenciales sesgos a favor de formas de entierro de momentos históricos o de la actividad antrópica actual, el otro método consistió en efectuar prospecciones a partir de transectas orientadas en forma paralela a la costa.

Ambas estrategias fueron aplicadas en dos microambientes con características contrastantes que cubren entre ambos una superficie de $595.000 \mathrm{~m}^{2}$. Por un lado, en el espacio costero comprendido entre Punta Paraná y la posición definida por las coordenadas 54은 51' 34" S y 670 53' 15" O (al oeste de Puerto Remolino) donde dominan claramente laderas rocosas y paleoplayas sobre geoformas glaciarias, con abundancia de rajas y paredes de roca y con presencia de aleros. El otro microambiente se ubica en las bahías Cambaceres Interior y Exterior, entre el río Varela y la laguna Aguas Malas; allí el paisaje está configurado por geoformas de origen glaciar, los lugares con rajas o paredes de roca son pocos frecuentes, no hay aleros grandes y no hay extensiones con paleoplayas. Los tramos de costa incluidos fueron de 11,7 km en el primer tramo y $12,1 \mathrm{~km}$ en las bahías Cambaceres. La prospección dirigida fue practicada también en la zona de Escarpados, la margen este del lago Roca y en los depósitos glaciarios de la bahía Brown. En ambos tipos de muestreo se implementaron exploraciones superficiales y subsuperficiales.

Estas tareas de búsqueda se enfrentaron a 
tres factores limitantes:

- Dinámica del paisaje: los rasgos de los afloramientos rocosos que observamos actualmente pueden tener poco que ver con los existentes en el pasado. Esto se debe, en parte, a que Tierra del Fuego es una zona sísmica, siendo las oquedades rocosas y los pequeños aleros rasgos del paisaje sensibles a este tipo de fenómeno. Por otro lado, las raíces de Nothofagus crecen dentro de pequeñas fisuras, provocando con el tiempo fracturas y desplazamientos importantes de rocas. O tro factor que afecta al paisaje arqueológico es el autorraleo de los Nothofagus (Borrero y Muñoz 1999): estos árboles, al caer, mueven de lugar grandes fragmentos de rocas e importantes volúmenes de sedimento en los cuales se fijaban sus raíces. Estos procesos, considerados en escalas temporales amplias, pudieron haber modificado sustancialmente el paisaje en el cual se desarrollaron las prácticas mortuorias.

- Preservación ósea: también debe contemplarse que las condiciones de preservación de restos humanos son variables, dependiendo del pH de los depósitos. En la región del canal Beagle, en áreas sin cobertura forestal y sin drenaje desde turberas, el pH de los suelos oscila entre 4,2 y 4,7 (Arena et al. 2003). En cambio, las determinaciones de $\mathrm{pH}$ efectuadas en concheros varían desde 6,95 hasta 7,1 (Orquera y Piana 2000).

Aunque las expectativas de preservación son evidentemente más favorables en depósitos conchíferos $^{6}$ (Linse 1992), no efectuamos sondeos en estas estructuras fundamentalmente por no generar perturbaciones sobre estos depósitos antrópicos. Como paliativo a este sesgo, las búsquedas en concheros se efectuaron aprovechando cortes generados por erosión del mar, trazados de rutas, instalaciones de viviendas, huaqueo, etc. Esta vía alternativa, si bien careció de un carácter sistemático, resultó intensa por la cantidad de perfiles revisados. Se inspeccionaron 72 cortes expuestos de concheros en el tramo de costa comprendido entre la desembocadura del río Almanza y el casco de la Estancia Remolino. No se detectaron restos humanos durante estas prospecciones.

6 En efecto, en el canal Beagle se recuperan restos óseos de fauna en perfecto estado de preservación en depósitos conchíferos con cronologías próximas a los 6000 años radiocarbónicos AP (Orquera y Piana 1999a).
- Visibilidad: la espesa cobertura vegetal existente en la región condiciona marcadamente la visibilidad del registro en cuestión. Esta condición anula casi por completo la posibilidad de efectuar prospecciones superficiales por transectas en la casi totalidad de las áreas consideradas. Sólo en playas y en pequeños "claros" en bosques, con una visibilidad relativamente mayor, es posible realizar una exploración superficial del terreno.

Con estas limitaciones, las estrategias de muestreo antes explicitadas incluyeron alrededor de mil sondeos con resultados negativos, pero fue posible ubicar cuatro contextos mortuorios y un elemento humano aislado. Los primeros fueron hallados en distintos ambientes a partir de búsquedas dirigidas mientras que el elemento descontextualizado fue recuperado en una playa en ocasión de recurrir a transectas. Todos los entierros localizados (Paiashauaia I, Mischiuen III e Imiwaia Entierro I y II) fueron excavados. También excavamos dos contextos mortuorios previamente detectados: Shamakush Enterratorio y Acatushún (ver ubicaciones en Fig. 1).

A continuación describiremos las condiciones de hallazgo y disposición de los restos óseos humanos, presentando los resultados obtenidos de la excavación y del análisis inicial de los materiales recuperados.

\section{CARACTERÍSTICAS DE LOS CONTEXTOS MORTUORIOS EXCAVADOS}

Imiwaia Entierro $1\left(54^{\circ} 52,26^{\prime} S\right.$ y $\left.67^{\circ} 17,18^{\prime} 0\right)$

Fue localizado en un sector de bosque dentro de la localidad arqueológica Imiwaia, a unos 120 metros de distancia de la costa. La oquedad donde fueron hallados restos óseos humanos (de $130 \mathrm{~cm}$ de frente por una profundidad de entre 30 y $60 \mathrm{~cm}$ ) se encuentra en la parte superior de un afloramiento rocoso (Fig. 2). Sobre el límite exterior de esta oquedad se inicia una pendiente de seis metros de largo con un ángulo de $38^{\circ}$.

$L$ a dispersión de elementos recuperada en 2003 no mostró coherencia anatómica ni estratigráfica alguna. Las unidades identificadas correspondían a distintas regiones del esqueleto de un individuo subadulto: tibia derecha, fémur derecho, mandíbula, una vértebra dorsal, seis costillas, una rótula y un fragmento de ilion. El estado de preservación de los huesos es bueno, registrándose sólo la pérdida de la capa cortical 


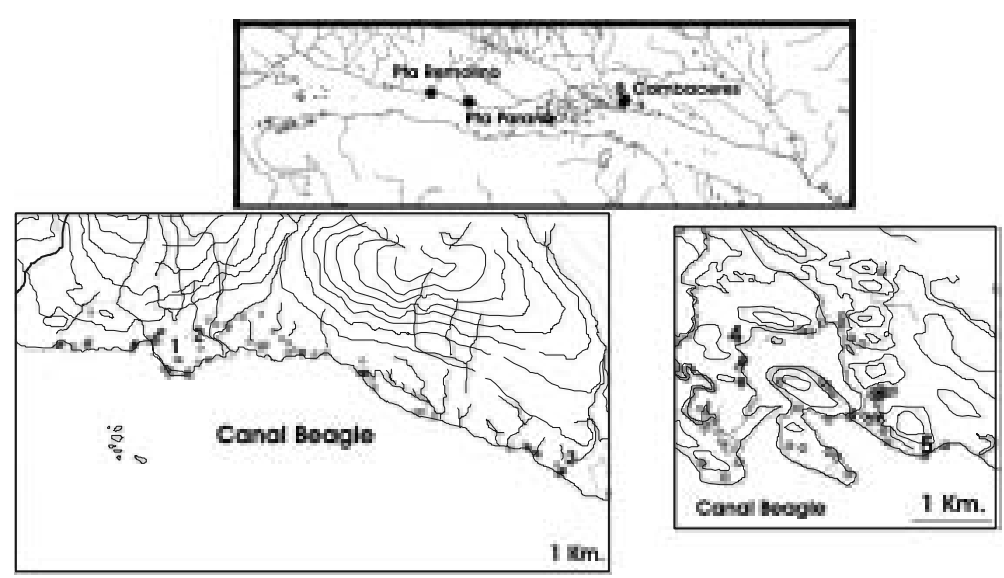

Fig. 1 Ubicación de los restos óseos humanos recuperados y su relación espacial con estructuras de concheros (representados con círculos). Referencias:

1. Mischiuen III; 2. Shamakush Entierro; 3. Paiashauia 1; 4. Imiwuaia Entierro 1 y $2 ; 5$. elemento óseo aislado.

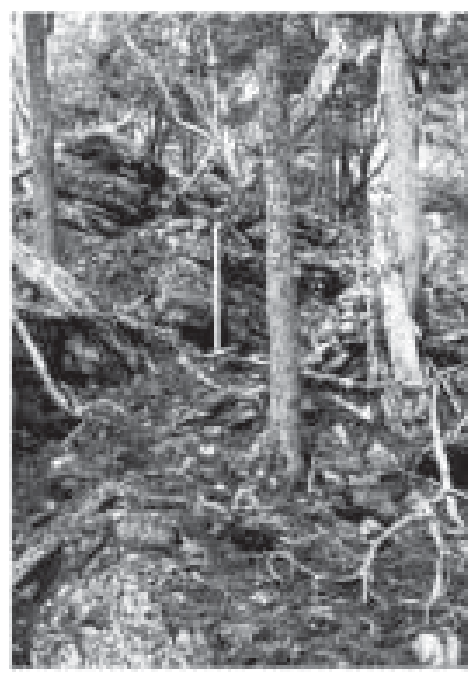

Fig. 2 Imiwaia Entierro 1. en algunas porciones. En este sector del registro también se hallaron dos especímenes óseos que no pudieron ser determinados anatómicamente.

La presencia de dos húmeros y una hemipelvis sobre la superficie de la pendiente (todos ellos con estadios avanzados de meteorización) nos llevó a reanudar las excavaciones al año siguiente, cubriendo así una extensión de $73,5 \mathrm{~m}^{2}$. En este sector se recuperaron 27 elementos óseos humanos aislados, con un rango de dispersión desde el lugar de depositación primaria de aproximadamente seis metros pendiente abajo. Parte de estos elementos corresponden a un segundo individuo adulto y de sexo femenino. Todos los elementos dispersos por la pendiente están fragmentados y presentan fisuras (en algunos casos de importantes dimensiones) y exfoliaciones, lo cual señala instancias de exposición constantes o por lapsos prolongados.

En suma, es escasa la integridad de los esqueletos que componen este contexto y todos los elementos se encontraron desarticulados e intercalados entre rocas. En toda el área también se observó una fuerte densidad de raíces de diversos tamaños. Basándonos sobre esta información contextual, consideramos que la remoción natural de rocas y la acción de raíces constituyeron los principales factores de destrucción de este contexto mortuorio.
Imiwaia Entierro $2\left(54^{\circ} 52,22^{\prime} \mathrm{S}\right.$ y $\left.67^{\circ} 17,16^{\prime} \mathrm{O}\right)$

Ubicado a 50 metros del "Entierro 1" y a 68 metros de la costa, nuevamente se trata de un pequeño abrigo rocoso -en este caso de 4 metros de largo y de entre 50 y $70 \mathrm{~cm}$ de profundidad (Fig. 3)-, en el que se halló depositada la porción superior de un esqueleto: sólo se encontraron representados los elementos desde el cráneo hasta la parte proximal de los cúbitos. Todos ellos estaban en posición anatómicamente articulada.

La edad del individuo se determinó mediante la medición de sus huesos (Scheuer y Black 2000). Los elementos disponibles para efectuar esta tarea fueron: clavícula, escápula, húmero y

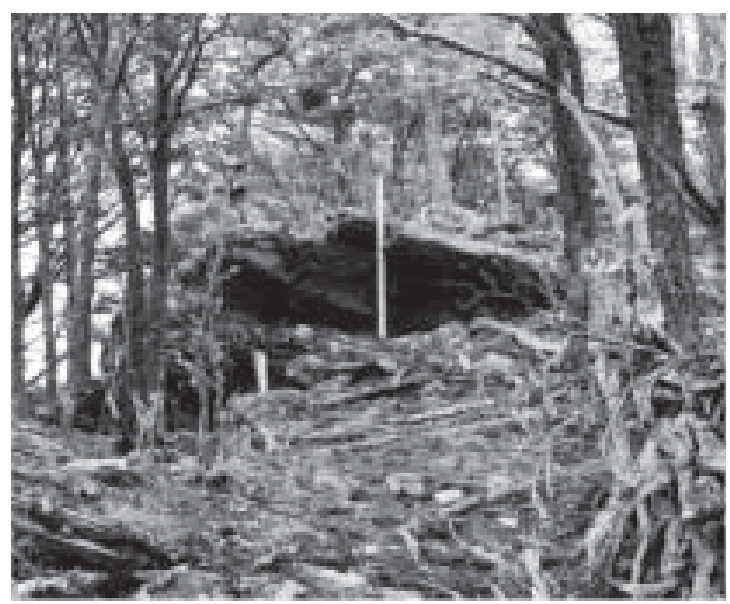

Fig. 3 Imiwaia Entierro 2. 
arco zigomático, todos ellos del lado izquierdo. EI rango de edad establecido para este individuo se extiende desde el nacimiento hasta los seis meses.

En términos generales, la preservación de los restos óseos recuperados es buena. La mayoría de los elementos están íntegros, a excepción de algunas costillas y del cúbito y húmero derechos. El cráneo estaba colapsado y mostraba indicios de meteorización sobre uno de los temporales, el cual afloraba en superficie antes de iniciar la excavación. Ningún sector del esqueleto estaba cubierto por rocas, aunque sí se hallaron algunas lajas contiguas al mismo.

En 2004 se decidió ampliar la excavación de este sitio con el fin de localizar los elementos de la porción faltante del esqueleto y analizar un posible proceso de dispersión de esos restos; esta ampliación tuvo una extensión de $9 \mathrm{~m}^{2}$. Durante la remoción de la hojarasca se obtuvo un fragmento de temporal perteneciente al mismo individuo registrado en este contexto, pero en el transcurso de la excavación no se hallaron otros restos óseos humanos.

\section{Shamakush Entierro I $\left(54^{\circ} 51,56^{\prime}\right.$ S y $\left.67^{\circ} 51,70^{\prime} 0\right)$}

Es un alero que se encuentra dentro de la localidad arqueológica Shamakush, a unos 670 $\mathrm{m}$ de la costa y $5 \mathrm{msnm}$ (Fig. 4). El contexto mortuorio ubicado dentro de este abrigo rocoso había sido inicialmente localizado y parcialmente perturbado por la actividad de aficionados. Esto exigió que en 1994 se realizaran las primeras recolecciones con el fin de conservar el material removido y expuesto en superficie. Durante este reconocimiento se recuperaron huesos pertenecientes a tres individuos, dos adultos y un

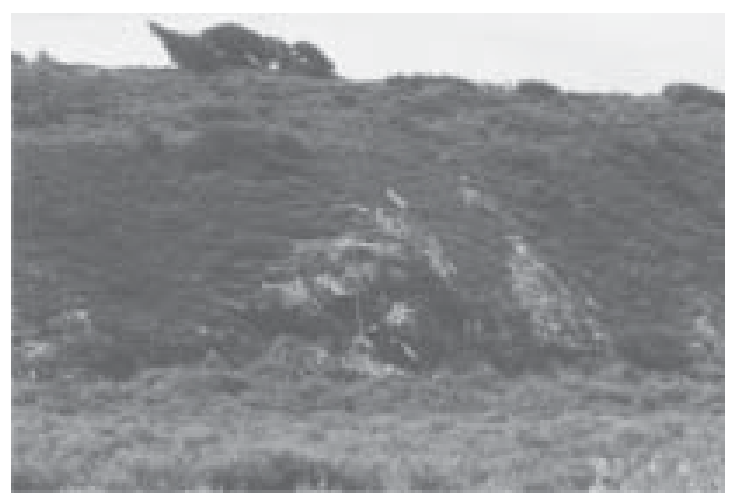

Fig. 4 Shamakush Entierro: vista general del alero. subadulto. Los elementos óseos estaban diseminados en un espacio reducido y algunos de ellos mostraban indicios de combustión.

Los restos correspondientes a cuatro individuos (dos adultos femeninos -SHE 1 y 2- , un adulto masculino -SHE 3- y un subadulto -SHE 4-) estaban depositados a escasa profundidad de manera totalmente desarticulada (con la excepción de unos pocos elementos que mostraban cierta coherencia anatómica entre sí). El estado de preservación de los huesos es variable, observándose desde elementos íntegros hasta la pérdida importante de ciertas porciones óseas en algunos de ellos. En este sector del conjunto también se registró un elevado grado de fragmentación, el cual está ligado fundamentalmente a procesos de combustión. Las tareas de reconstrucción llevadas a cabo hasta el momento señalarían que este factor incidió principalmente sobre huesos largos.

Subyacente a este conjunto de restos óseos humanos se halló una capa arqueológicamente estéril compuesta por rocas de caja y sedimento fino. Por debajo de ella se recuperaron restos óseos pertenecientes a dos individuos. Uno de ellos (SHE 5) está representado únicamente por los elementos que integran la articulación acromio-clavicular izquierda (húmero, clavícula y escápula), el restante consiste en un esqueleto en posición primaria (SHE 6). En este último, algunas regiones traslucieron importantes grados de modificación y pérdidas óseas. Por un lado, de los elementos correspondientes al brazo derecho sólo se recuperó la porción proximal del húmero. En el sector que debieron ser ocupados por los fémures se recobraron fragmentos de huesos calcinados. Los elementos correspondientes al tarso también estuvieron ausentes. De los miembros inferiores sólo fueron halladas las diáfisis de las tibias y los peronés, las cuales se encontraron en relación anatómica entre sí. No obstante, no fue posible determinar a cuál de los dos individuos (SHE 5 ó 6) corresponden estas unidades.

Dado el nivel de desarticulación y fragmentación de este conjunto, por el momento resulta difícil reconstruir o hacer una apreciación ajustada sobre la integridad de los distintos esqueletos. Debido a esta situación y a que por el momento no podemos descartar la posibilidad de que elementos pertenecientes a SHE 5 estén redepositados en el conjunto superior de este sitio, preferimos manejar una cifra conservadora 


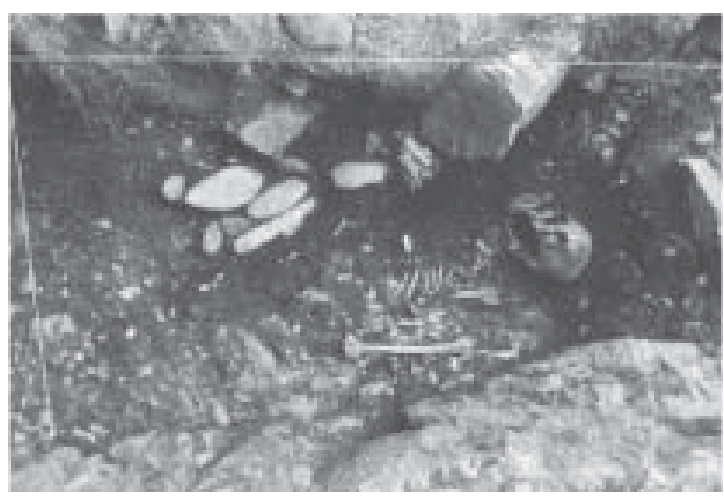

Fig. 5 Shamakush Entierro: vista de SHE 6 con artefactos líticos asociados.

de un mínimo de cinco individuos para este contexto. Asimismo resulta difícil definir si existió sincronicidad en la depositación de los cuerpos. No obstante, consideramos que al menos una reutilización de este alero se pudo haber dado con SHE 6, lo cual a su vez pudo haber contribuido a la desarticulación de los esqueletos allí emplazados previamente.

Un aspecto significativo de SHE 6, no registrado anteriormente en otros contextos mortuorios del canal Beagle, consiste en la asociación de este individuo con un conjunto instrumental lítico y óseo. No sólo esto, el conjunto era particularmente llamativo pues incluía dieciséis puntas líticas, seis bifaces, cuatro raederas, un punzón y múltiples fragmentos de huesos de ave decorados (estos últimos ubicados a la altura del cuello) que implican la presencia de al menos cuatro cuentas de collar (Fig. 5). Una de las raederas estaba depositada contra el lateral derecho del cráneo mientras que un punzón óseo apoyaba sobre el lateral izquierdo. El sector de la estratigrafía donde fue hallado SHE 6 también permitió definir los limites de una fosa de inhumación para este individuo. El análisis exhaustivo y la evaluación de esta información contextual se llevará a cabo en una futura contribución.

SHE 6 también estaba asociado a abundantes concentraciones de carbón y presentó indicios de combustión parcial en el cráneo. Las cuentas de collar ubicadas a la altura del cuello y el punzón asociado al cráneo también evidenciaban indicios de combustión. Del análisis efectuado sobre una muestra de carbón asociada resultó una antigüedad de $620 \pm 60$ años ${ }^{14} \mathrm{C}$ AP (AC 1680).

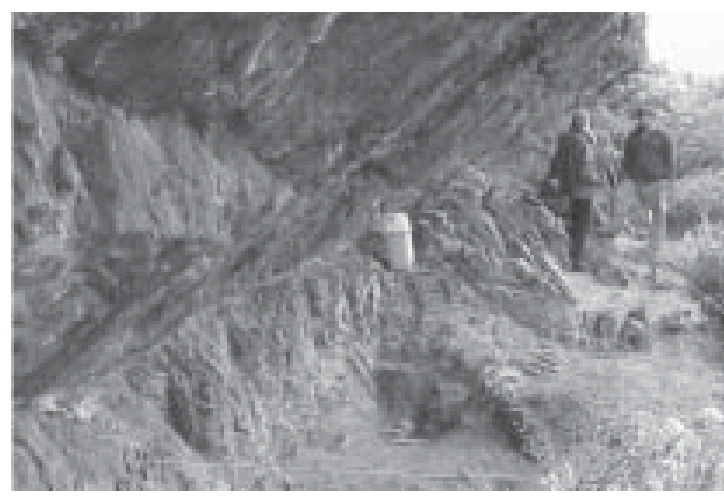

Fig. 6 Mischiuen III: vista del interior del alero.

Mischiuen $\mathrm{III}^{7}$ (54은 $51,67^{\prime}$ S y $67^{\circ}=52,08^{\prime} \mathrm{O}$ )

Es un alero de 15 metros de largo por un metro y medio de profundidad ubicado sobre una pared del afloramiento rocoso próximo al casco de la Ea. Remolino (Fig. 6). Este abrigo rocoso dista unos 290 metros de la costa y se eleva unos $4 \mathrm{msnm}$. Aleros de estas dimensiones son muy poco frecuentes en la región. También este sitio se encuentra próximo a estructuras de conchero.

En una excavación dirigida en 2001 por la Dra. Vila Mitja se hallaron restos pertenecientes a dos individuos. Uno de ellos se encontraba en posición primaria flexionada, con los huesos de ambas manos junto al cráneo (Fig. 7). Las falanges del pie y los metatarsianos, en cambio, no conservaban sus posiciones anatómicas primarias. Evaluando el grado de fusión de las epífisis en los huesos largos se estableció que estos restos óseos pertenecieron a un individuo femenino subadulto de entre 14 y 16 años (Vila M. et al. 2002, Vila M. 2004). J unto al cráneo de este esqueleto se encontró asociado un peroné perteneciente a un segundo individuo. El análisis radiocarbónico por AMS de una muestra ósea del primer esqueleto dio un fechado de $625 \pm 25$ AP (KIA-19492) ${ }^{8}$ (Vila M. com. pers.).

7 Mishiuen III fue detectado durante las tareas del PIP 4302 CONICET y luego excavado como parte del Proyecto «Sociedad y Ritual en los últimos cazadores-recolectores del Canal Beagle (Tierra del Fuego, Argentina)», Ministerio de Educación y Cultura de España bajo la dirección de la Dra. Asunción Vila Mitja y la participación de uno de nosotros (AT).

8 Código de laboratorio del Institut Royal du Patrimione Artistique, Bruselas. 


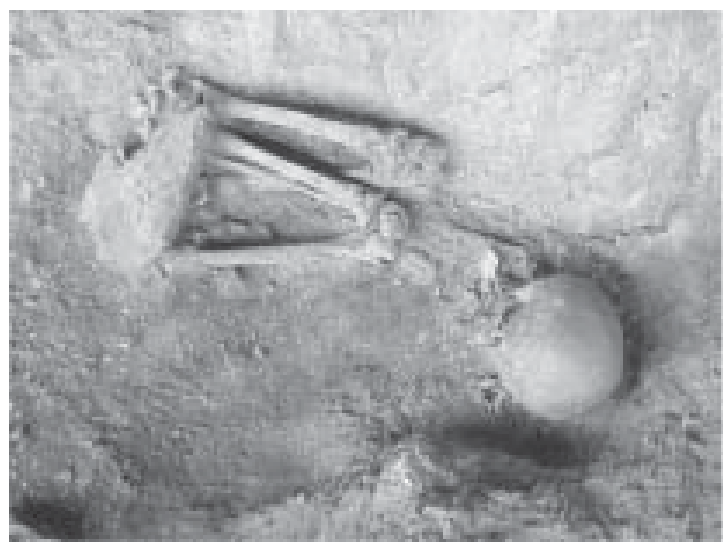

Fig. 7 Mischiuen III: vista del individuo 1 (tomada de Vila M. et al. 2002).

Dado que la señal isotópica de la relación ${ }^{13} \mathrm{C} /{ }^{12} \mathrm{C}(11.1 \% \text {; AIE } 11720)^{9}$ indica una alimentación compuesta predominantemente por recursos marinos (Tessone et al. 2003), la cronología señalada debe estar afectada por Efecto Reservorio. Para la región del canal Beagle, este factor fue estimado en aproximadamente 600 años (Albero et al. 1986 y 1988). No obstante, allí no toda la fauna marina se encuentra influida con la misma intensidad; dependiendo de las condiciones microambientales los moluscos pueden generar distintas señales isotópicas e incluso no mostrar Efecto Reservorio alguno (Albero et al. 1988, Bogomil et al. 1998). Por otro lado, la fauna marina -si bien dominante en la dieta- no necesariamente debe haber sido la única clase de ingesta. Por ende consideramos que la cronología señalada constituye una edad máxima a la que debe descontarse un rango no estimable de Efecto Reservorio inferior a 600 años.

Con el fin de localizar más elementos correspondientes a este individuo, durante la excavación de 2001 se amplió el área de excavación unos $2 \mathrm{~m}^{2}$, sin embargo sólo se hallaron algunos fragmentos de costillas, vértebras y huesos no determinados.

El grado de preservación de los restos correspondientes al individuo subadulto es muy bueno, pero no la integridad de su esqueleto: estaban presentes muy pocos elementos de la región torácica (tres vértebras cervicales y una primera costilla). Estudios tafonómicos desarrolla- dos en el área mostraron que la actividad carroñera de los zorros constituye el principal factor de dispersión en carcasas de ungulados (Estévez y Mameli 2000). No obstante no consideramos que ésta haya sido la causa de la ausencia de ciertos elementos óseos toráxicos, pues no detectamos indicios de actividad carroñera en los elementos óseos remanentes y sostenerlo implicaría el interjuego de una serie de suposiciones sobre las pautas de desarticulación de zorros y el modo de depositación del cadáver.

Para explorar el grado de dispersión de los elementos faltantes y los procesos o agentes implicados en dicho proceso, en 2004 retomamos las excavaciones en la sector exterior del alero. Así el área excavada se extendió 10,25 m² sobre el barranco al pie del alero, cuya pendiente es de $23^{\circ}$. Fueron 38 lo restos óseos humanos recuperados en esa ocasión, los cuales conformaban una dispersión con un rango máximo de cuatro metros desde el lugar donde se encontraba depositado el esqueleto en posición primaria. En su casi totalidad correspondían a fragmentos de vértebras y costillas, pero también se recuperó una clavícula. Resulta interesante destacar que las vértebras presentes en este conjunto completan el tramo cervical de la columna del individuo subadulto y articulan de manera exacta con las vértebras halladas en el contexto primario. Fisuras, exfoliaciones y marcas de radículas sólo están presentes en los restos óseos recuperados en el sector exterior del alero, lo que señala instancias de exposición en la historia post-depositacional de estos elementos. En estos elementos óseos desarticulados tampoco se identificaron marcas dejadas por cánidos. En suma, consideramos que los factores responsables de la desarticulación y exposición de parte del esqueleto pudieron ser varios, incluyendo posiblemente desde la simple destrucción de los tejidos blandos combinado con posteriores movimientos gravitacionales hasta perturbaciones provocadas por la acción de conejos (que fueron plaga en el lugar). Respecto de esto último se destaca la presencia de marcas provocadas por roedores, principalmente so bre fragmentos de costillas, como así también la presencia de dos esqueletos completos y elementos aislados de roedores grandes (conejos) en la extensión excavada por fuera del alero. 


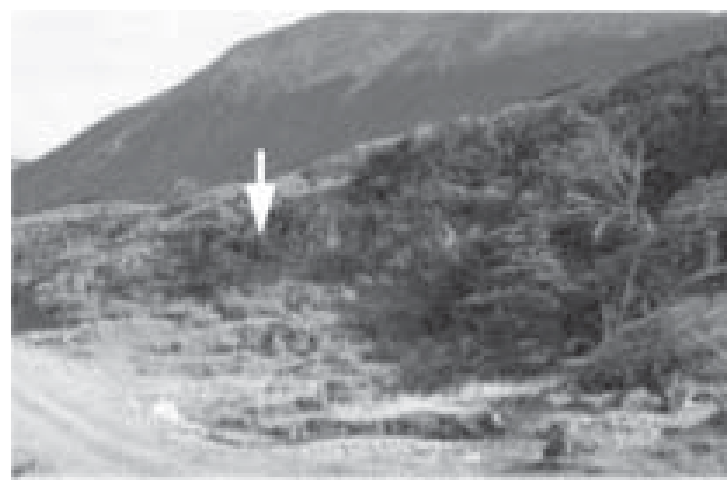

Fig. 8 Vista de Paiashauia 1

(la flecha indica la ubicación del sitio excavado).

Se trata de un contexto primario de un individuo adulto emplazado sobre un escalón a media altura de un afloramiento rocoso contiguo a la desembocadura del río Paraná (Ea. Remolino), a 33 metros de distancia de la costa y a 6 msnm. Este sitio yace adyacente a una pared de dicho afloramiento, tanto al pie como por encima de él se visualizan numerosos concheros (Fig. 8).

Superpuesto al contexto mortuorio estaba depositada una capa delgada de sedimento con valvas, predominantemente de M ytilus sp., y con presencia de otros restos de fauna, entre los que predominaban huesos de pinnípedos y aves. Fue muy escaso el material artefactual recuperado. Subyacente a esta capa conchífera se extrajo una gruesa acumulación de rocas y sedimento que cubría los restos óseos humanos. Las rocas, de diversos tamaños, tenían las mismas propiedades que la formación rocosa contigua y cubrían por completo al esqueleto. Esta acumulación pudo ser generada tanto por procesos naturales (e.g.: desprendimientos o lavados de pendiente) como por colocación intencional (sea ella total o parcial), pero consideramos que la alta integridad del esqueleto y el buen grado de articulación de los elementos hace más difícil defender el primer argumento.

El esqueleto tenía posición extendida con las manos superpuestas sobre la pelvis y las extremidades inferiores juntas desde las rodillas hasta los pies (Fig. 9). Prácticamente todo el esqueleto estaba articulado en una posición anatómica perfecta; en este sentido, las únicas excepciones estaban dadas por ambas clavículas, a las que se encontró desplazadas hacia el sector me-

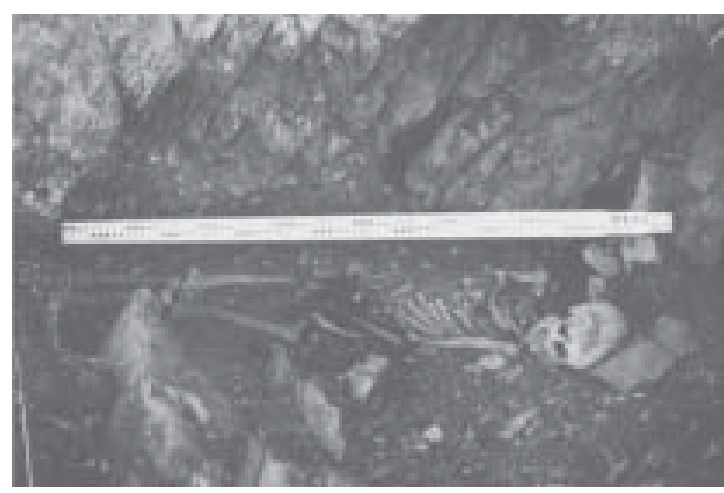

Fig. 9 Paiashauia 1: vista del esqueleto.

dio de la región torácica. El grado de preservación de los elementos óseos es en general bueno. Sólo se advirtió fragmentación ósea en el sector inferior de la columna vertebral, haciéndose más notoria en la primera y segunda vértebra lumbar. $\mathrm{L}$ a incidencia de otros procesos de modificación ósea (e.g.: raíces, agentes animales, etc.) es muy poco significativa, sólo cabe destacar la presencia de tinciones sobre una amplia porción del esqueleto como producto de la concentración de dendritas de manganeso.

\section{Acatushún $\left(54^{\circ} 52,42^{\prime}\right.$ S y $67^{\circ} 19,91^{\prime}$ O)}

Es un entierro primario de un individuo adulto, depositado en un conchero extenso en las cercanías del casco de la Estancia Harberton a $4 \mathrm{~m} \mathrm{snm}$. y 40 metros de la costa (Fig. 10). Este esqueleto había sido detectado e inicialmente excavado por la Dra. Rae Natalie Prosser de Goodall, quien luego de exponerlo volvió a cubrirlo con materiales del conchero. Fue posible

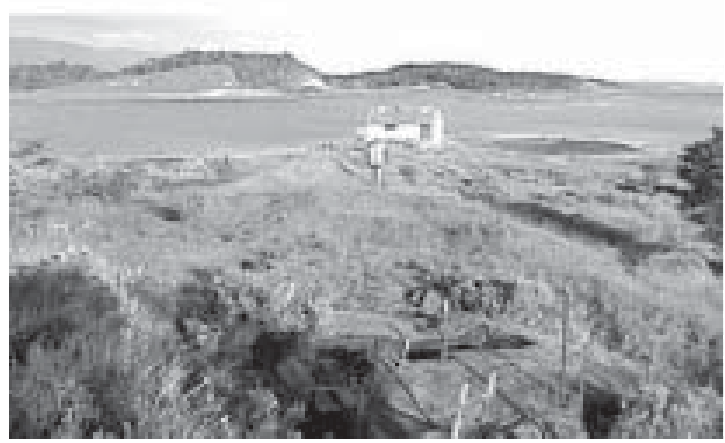

Fig. 10 Vista de Acatushún. 


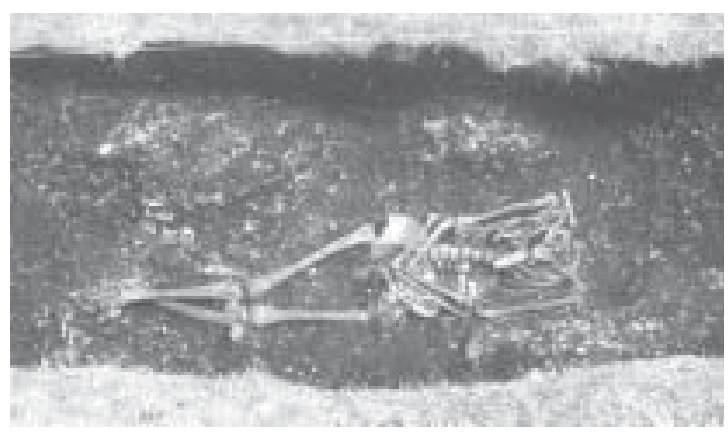

Fig. 11 Acatushún: vista del esqueleto

(las flechas señalan la ubicación de los botones).

recuperar los límites de la excavación de G oodall, pero no pudimos visualizar otros rasgos asociados a esta inhumación. La posición del cuerpo era extendida, con las manos superpuestas sobre la pelvis y los miembros inferiores cruzados a la altura de los tobillos (Fig. 11). Los tarsianos y metatarsianos presentaban una leve dispersión, pero las restantes partes del esqueleto se encontraron anatómicamente articuladas. El cráneo estaba ausente debido a la actividad de aficionados en el lugar posteriormente a la intervención de la Dra. Goodall, cuyas fotografías revelan que en la década del ' 70 el cráneo aún se conservaba en su posición primaria. Todos los elementos presentan un grado de preservación excelente: no se observaron fracturas ni otros indicios de modificación ósea. Asociado a la columna vertebral se encontraron seis botones, lo cual permite inferir que el entierro corresponde a momentos históricos.

En el mismo conchal en 1972 ya se habían recuperado -nuevamente por la intervención de aficionados- restos óseos pertenecientes a tres esqueletos (MFM 855, 856 y 2412), dos de individuos infantiles y el restante de un individuo perinatal que fueron entregados al Museo del Fin del Mundo. El esqueleto de este último también tenía botones asociados.

\section{Elementos aislados}

En la línea de mareas altas de una playa cerca de la desembocadura de Aguas Malas (54은 $53^{\prime} 40^{\prime \prime} \mathrm{S}$ y $67^{\circ} 15^{\prime} 01^{\prime \prime} \mathrm{O}$ ), una pequeña laguna poco profunda que drena hacia la playa, se halló un cúbito derecho redepositado. Es el único hallazgo que pudo ser efectuado a partir de transectas. En la desembocadura de esta laguna también había sido detectada una mandíbula en
1995. El cúbito tiene las epífisis fuertemente meteorizadas y la superficie de la mandíbula está algo erosionada, en ambos casos probablemente por acción del mar. No se advirtieron marcas de otros factores tafonómicos.

\section{ESTADO ACTUAL DEL CONOCIMIENTO Y CONSIDERACIONES FINALES}

La información arqueológica sobre prácticas asociadas a la muerte y modos de disposición de restos óseos humanos en el canal Beagle, como ya se ha mencionado, es escasa. No obstante, se pueden realizar algunas observaciones preliminares de los diversos factores que inciden sobre la distribución, visibilidad y preservación de los restos óseos humanos a partir de la nueva evidencia generada por las prospecciones y excavaciones aquí presentadas (Tabla 1 ).

Primero es necesario destacar que los contextos mortuorios en la región del canal Beagle son "escenarios" de bajísima visibilidad arqueológica. Este factor no sólo obedece a las características del ambiente (e.g.: intensa cobertura vegetal), sino también a los procesos culturales y naturales implicados en la formación de este registro. En este sentido, se detectó variabilidad en las historias tafonómicas: desde la intervención de factores abióticos hasta perturbaciones provocadas por agentes animales y acciones antrópicas recientes. Los restos óseos hallados en aleros y pequeños abrigos rocosos parecen haber sufrido las mayores modificaciones. Las perturbaciones ocurridas en estas geoformas rocosas pueden ser atribuidas a varios factores. Los desprendimientos y la remoción gravitacional de rocas (que incluso pueden ser potenciadas por episodios sísmicos), el autorraleo de Nothofagus y las alteraciones producidas por animales son algunas de las variables más significativas. Estas condiciones dinámicas y poco favorables para la preservación generan bajas expectativas de detección de restos humanos de momentos tempranos de ocupación de la región, al menos en estos tipos de contextos.

Los restos humanos con información cronológica son muy pocos, en la mayoría de los casos por asociación con fechados sobre carbón o con materiales de origen europeo. El único dato directo se da en el individuo subadulto de Mischiuen III, que consiste en una edad máxima de $625 \pm 25$ AP a la que, como quedó dicho, debe descontarse algún grado no estimable de efecto 


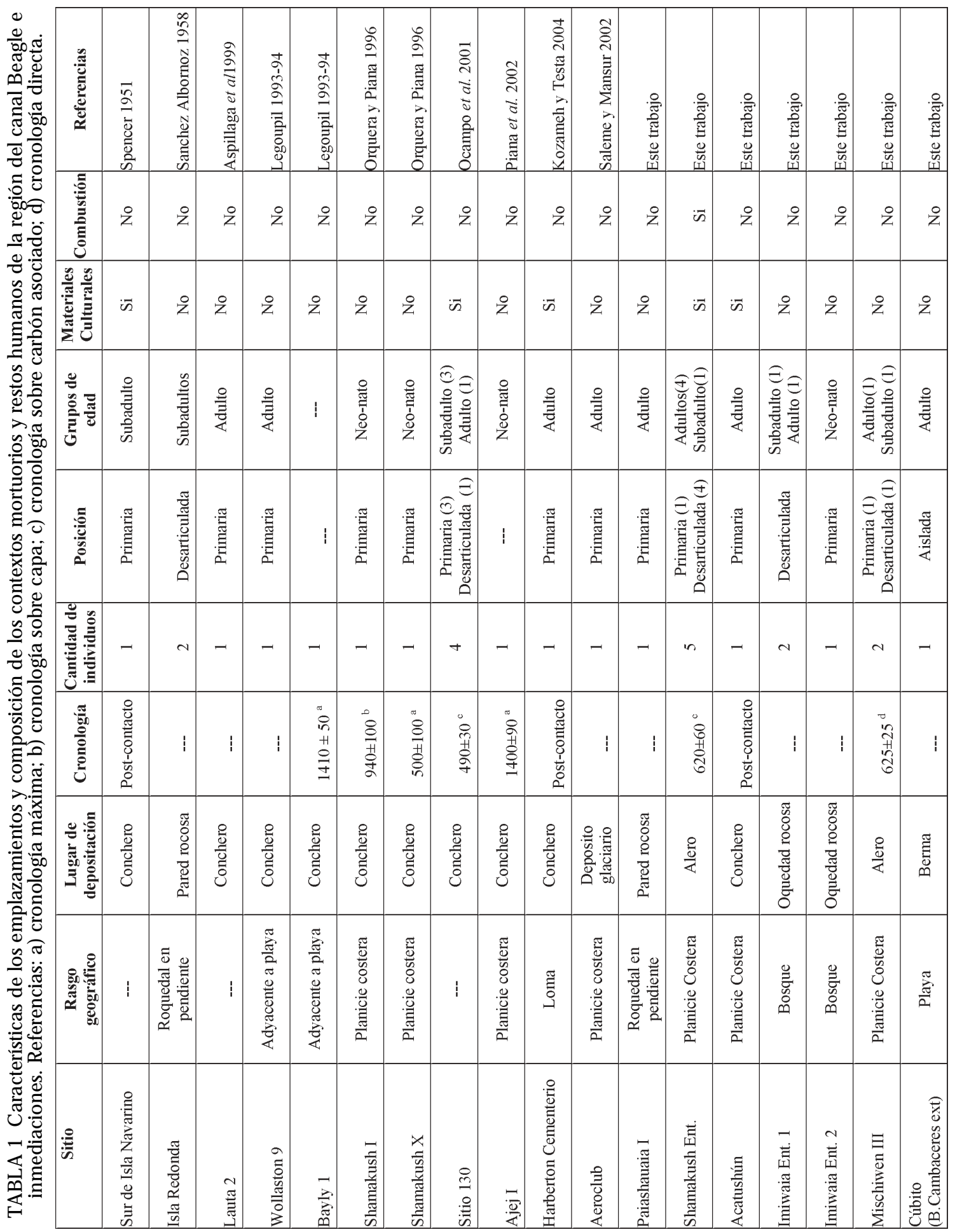


reservorio. Por el momento, la información cronológica ubica a los contextos aquí analizados en los últimos 1400 años radiocarbónicos, pero se agrupan mayormente en los 600 años más recientes.

Los rangos etarios de los individuos recuperados en concheros y geoformas mencionadas conducen a descartar la selección de uno u otro ambiente como dependiente de la edad del individuo. Tampoco se observa una relación entre ese factor y la forma de depositación de los esqueletos. Esto contradice algunas afirmaciones del registro etnohistórico, realizadas durante fines del siglo XIX y principios del XX (Bridges 1866:20 y 1869:119; Koppers 1924:136).

A excepción de los elementos aislados, los hallazgos de restos óseos humanos están por debajo de los 30 msnm y a menos de $700 \mathrm{~m}$ de la costa. Esto coincide con la densidad máxima de los sitios (concheros) detectados (ver Barceló et al. 2002). En este mismo sentido, las distancias máximas de los restos que no fueron hallados en concheros no exceden los 200 metros de alguna estructura de conchero. Por lo tanto, teniendo en cuenta que:

a) la búsqueda de contextos mortuorios de ningún modo se ha restringido a lugares cercanos a concheros; y

b) que los resultados de las prospecciones y excavaciones sostienen una alta relación espacial entre los lugares de residencia y de depositación de cadáveres, nada conduce a presumir segregación espacial entre lugares reservados para conductas mortuorias y para la realización de otras actividades. Tampoco parece haber existido una formalización (sensu Pardoe 1988) o uso exclusivo de espacios destinados a la depositación de cadáveres antes de la influencia de los misioneros anglicanos; los cementerios conocidos en los que se enterraron aborígenes (e.g.: Mejillones, Puerto Remolino, Harberton, Ushuaia, etc.) estuvieron todos dentro del área de influencia y control de misioneros o pobladores occidentales. No obstante, los casos antes presentados conducen a suponer que aún en el período etnohistórico se dispusieron cadáveres de modo aislado y disperso.

En los antecedentes arqueológicos predominaban los entierros individuales. Sin embargo, hay lugares en los que se encontró representado más de un individuo. De aleros o rajas de roca se extrajeron restos de un mínimo de cinco individuos en Shamakush Entierro y dos en Imiwaia
Entierro 1, Mishiuen III e Isla Redonda. De conchales se extrajeron cuatro individuos en el sitio C 130. Por otra parte, tanto en Shamakush Entierro como en Mischiuen III solo un individuo fue encontrado en posición primaria; el resto del registro bioarqueológico, a excepción de Paiashauaia y Acatushún, está representado por hallazgos aislados o contextos secundarios. En el estado actual del conocimiento resulta más plausible la reutilización de algunos espacios en lapsos amplios de tiempo que inhumaciones múltiples y simultáneas.

Por el momento los contextos mortuorios conocidos han sido interpretados -explícita o implícitamente- como primarios y la información arqueológica y contextual con que se cuenta tiende a sostener esta interpretación. No existen evidencias de descarne o de entierros secundarios (sensu Ubelaker 1989), por lo que no hay indicios de tratamiento de los cuerpos en instancias previas a la depositación final de los restos.

La presencia de ajuar queda arqueológicamente documentada sólo en SHE 6, Sitio C 130 y Harberton Cementerio. Sin embargo, la frecuencia de su práctica puede estar afectada por la destrucción post-depositacional de implementos confeccionados con materiales perecederos tales como cueros, maderas, juncos, etc. Aun cuando la preservación en concheros es excelente, estos materiales fueron hallados muy ocasionalmente en las excavaciones arqueológicas de la región. Las condiciones microambientales de aleros y rajas de roca del canal Beagle perjudican aun más la preservación de tales materiales. Esta situación marca un caso opuesto a lo registrado en cuevas y aleros del fiordo Ultima Esperanza y otros sectores del archipiélago fueguino (Legoupil y Prieto 1991; San Román y Morello 2001; Prieto y Cárdenas 2001).

En cuanto a la colocación de los cuerpos, se han encontrado esqueletos tanto en forma flexionada como extendida. Estas posiciones no presentan relación alguna con el medio en que se lo depositó o con otros rasgos del contexto, ni con sexo o edad. Por lo tanto, si bien los datos son escasos, no parece que esta variabilidad pueda obedecer a un factor en particular.

La información etnohistórica sobre la combustión en actividades mortuorias es abundante e indica que su realización era frecuente (ver Orquera y Piana 1999b). En el registro arqueológico, en cambio, la detección de esta práctica es muy escasa. Entre todos los restos óseos de la 
colección del Museo del Fin del Mundo, sólo un caso (MFM 1607) muestra indicios de combustión, que puede o no ser postdepositacional. SHE 6 es el único ejemplo hasta el momento en el cual hay combustión -parcial- de algunos elementos y se hallaron restos de carbón asociados.

En suma, los resultados alcanzados por las investigaciones aquí enunciadas condujeron a revisar conceptos previos. En la información discutida hay ciertas regularidades: disposición primaria de cadáveres en concheros o en afloramientos rocosos, en cercanía o superposición con lugares residenciales, sin mayor segregación espacial específica ni formalización de espacios mortuorios. Pero hay alta variabilidad cuando se interjuega en relación con otras variables como presencia o no de ajuar, posición flexionada 0 estirada del esqueleto, ambiente de depositación, etc.

\section{AGRADECIMIENTOS}

Las prospecciones y excavaciones efectuadas entre 2001 y 2004 fueron parte de las investigaciones de los proyectos CONICET PIP 4302 y 6186. La excavación del enterratorio de Harberton Cementerio estuvo a cargo del Lic. Albert Montull.

Agradecemos a la Dra. Asunción Vila M. habernos suministrado informes sobre el enterratorio de Mischiuen III y su datación. A la Dra. Myrian Álvarez agradecemos los análisis de microdesgaste citados en el texto.

Agradecemos a Luis Orquera, Dánae Fiore, Ramiro Barberena y Martín Vázquez por las lecturas efectuadas so bre diversos bo rradores de este trabajo. Marilén Fernández, J imena Oria y Mariano Reyes colaboraron en las tareas de prospección y excavación. Martín Vázquez participó en la excavación de Shamakush Entierro y aportó interesantes ideas para la interpretación de este sitio, además de asistirnos en el procesamiento de las imágenes de este trabajo.

\section{BIBLIOGRAFÍA}

ALBERO M. C., F. E. ANGIOLINI y E. L. PIANA 1986. Discordant ages related to Reservoir Effect of associated archaeological remains from Túnel site (Beagle Channel, Argentine Republic). Radiocarbon 28 (2): 748-753. Inglaterra.

ALBERO M. C., F. E. ANGIOLINI y E. L. PIANA 1988. Holocene ${ }^{14} \mathrm{C}$ Reservoir Effects at Beagle Channel (Tierra del Fuego, Argentine Republic). Quaternary of South America and Antarctic Peninsula 5: 59-71. A. A. Balkema Publishers, Rotterdam, Holanda.

ARENA M. I., G. VATER y P. PERI 2003. Fruit production of Berberis buxifolia Lam in Tierra del Fuego. HortScience 38 (2): 200-202.

ASPILLAGA E., C. OCAMPO y P. RIVAS 1999. Restos óseos humanos de contextos arqueológicos del área de isla Navarino: indicadores de estilos de vida en indígenas canoeros. Anales del Instituto de la Patagonia 27:123135. Punta Arenas, Chile.

BARCELÓ J. A., E. L. PIANA y D. R. MARTINIONI 2002. Archaeological spatial modelling: a case study from Beagle Channel (Argentina). Archaeological Informatics: Pushing the Envelope. Computer Applications and Quantitative Methods in Archaeology. BAR Series 1016: 351-360. Archaeopress, Londres, Inglaterra.

BARRIENTOS G. 2002. The archaeological analysis of deathrelated behaviors from an evolutionary perspective. En Perspectivas Integradoras entre Arqueología y Evolución, pp. 221-253. Editado por Martínez G. y J. L. Lanata. INCUAPA, Olavaria, Argentina.

BARRIENTOS G., R. A. GOÑI, A. F. ZANGRANDO, M. DEL PAPA, S. GARCÍA GURAIEB, M. J. ARREGUI y C. NEG RO 2006. Human taphonomy in southern Patagonia. En prensa en Taphonomy and Archaeology in Argentina. Editado por M. G utiérrez, G. Barrientos, M. Salemme, L. Miotti y G. Mengoni Goñalons. British Archaeological Reports, Internacional Series, Oxford, Inglaterra.

BOGOMIL O., A. ALVAREZ, J. ARGULLÓS y E. L. PIANA 1998. Determination of the paleotemperature in Beagle Channel (Argentina) through stable isotope composition of Mytilus edulis shells. Quaternary of South America and Antarctic Peninsula 11: 47-71. A. A. Balkema Publ., Rotterdam, Holanda.

BORRERO L. y S. MUÑOZ 1999. Tafonomía en el bosque patagónico. Implicaciones para el estudio de su explotación y uso por las poblaciones humanas de cazadores-recolectores. En Soplando en el Viento... Actas de las III J ornadas de Arqueología de la Patagonia, pp. 43-56. Neuquén-Buenos Aires, Argentina.

BRIDGES T. 1866. Carta publicada en A Voice of South America XIII: 181-184 y 201-214. Londres, Inglaterra.

BRIDGES T. 1869. Carta publicada en South American M issionary Magazine III: 113-119. Londres, Inglaterra.

DILLEHAY T. 1997. ¿Dónde están los restos óseos humanos del período pleistoceno tardío? Problemas y perspectivas en la búsqueda de los primeros americanos. Boletín de Arqueología PUCP 1: 55-63.

ESTÉVEZ ESCALERA J . y L. MAMELLI 2000. Muerte en el canal: experiencias bioestratigráficas controladas sobre la acción sustractiva de cánidos. Archaeofauna 9: 7-16.

GUICHÓN R. 2000. Agenda para una evaluación en la Antropología Biológica de Patagonia Austral. En Desde el País de los Gigantes. Perspectivas arqueológicas en Patagonia, Tomo I, pp. 99-106. UNPA, Río Gallegos, Argentina.

GUICHÓN R. A., A. S. MUÑOZ y L. A. BORRERO 2000. Datos para una tafonomía de restos óseos humanos en Bahía San Sebastián, Tierra del Fuego. Relaciones de la Sociedad Argentina de Antropología XXV: 297-313. Buenos Aires, Argentina.

GUICHÓN R. A., R. BARBERENA y L. A. BORRERO 2001. ¿Dónde y cómo aparecen los restos óseos humanos 
en Patagonia Austral?. Anales del Instituto de la Patagonia Serie Ciencias H umanas, 29:103-118. Punta Arenas, Chile.

GUSINDE M. 1937. Die Feuerland-Indianer. Tomo II: Die Yamana. Mödling, 1500 pp. Citas tomadas de la traducción al castellano: CAEA, Buenos Aires, 1986, 3 vols.

HYADES P. 1885. Une année au Cap Horn. Le Tour du Monde 59: 385-416.

KOPPERS W. 1924. Unter feurland- indianer (eine foschungsreise zu den südlichsten bewohnern der erde mit M. Gusinde). Strecker und Schröeder, Stuttgart, 241 pp. Cita tomada de la versión española: Entre los fueguinos. Universidad de Magallanes y Programa Chile Austral, U.E. Punta Arenas, Chile 1997.

KOZAMEH L. F. y N. TESTA 2004. Tierra del Fuego. Un poblador tardío del canal Beagle. Análisis esqueletal y dentario. En Contra Viento y Marea. Arqueología de la Patagonia, pp. 733-744. Compiladores Civalero M. T., P. M. Fernandez y A. G. Guraieb. INAPL, Buenos Aires, Argentina.

LARSEN C. S. 1997. Bioarchaeology: Interpreting Behavior from the Human Skeleton. Cambridge University Press.

LEGOUPIL D. 1993-94. El archipiélago del Cabo de Hornos y la costa sur de la isla Navarino: poblamiento y modelos económicos. Anales del Instituto de la Patagonia 22: 101-121. Punta Arenas, Chile.

LEGOUPIL D. y A. PRIETO 1991. Sepultura de niños canoeros en un abrigo pintado en Ultima Esperanza, Chile. Anales del Instituto de la Patagonia 20:133138. Punta Arenas, Chile.

LINSE A. R. 1992. Is bone safe in a shell midden?. En Deciphering a shell midden, pp. 327-345. Editado por J ulie K. Stein. Academic Press.

MARTIN F. M. 2004. Tendencias tafonómicas en el registro óseo humano del norte de Tierra del Fuego. En Temas de Arqueología. Arqueología de la Isla Grande de Tierra del Fuego, pp. 107-133. Compilado por Borrero L. y R Barberena. Editorial Dunken. Buenos Aires, Argentina.

OCAMPO C., E. ASPILLAGA y P. RIVAS 2001. Entierros en Terrazas Altas, Ensenada Villarino (Sitio N 130 isla Navarino). Informe Proyecto FONDECYT 1980654. MS.

ORQUERA L. A. y E. L. PIANA 1996. EI Sitio Shamakush I. Relaciones de la Sociedad Argentina de Antropología XXI: 215-265. Buenos Aires, Argentina.

ORQUERA L. A. y E. L. PIANA 1999a. Arqueología de la región del canal Beagle (Tierra del Fuego, República Argentina). Sociedad Argentina de Antropología, Buenos Aires, Argentina, 146 pp.

ORQUERA L. A. y E. L. PIANA 1999b. La vida material y social de los Yámana. Eudeba-IFIC, Buenos Aires, Argentina, $567 \mathrm{pp}$.

ORQUERA L. A. y E. L. PIANA 2000. Composición de conchales de la costa del canal Beagle (Tierra del Fuego, República Argentina) -Primera Parte-. Relaciones de la Sociedad Argentina de Antropología XXV: 249-274. Buenos Aires, Argentina.

PARDOE C. 1988. The cemetery as symbol: the distribution of Aboriginal burial grounds in southeastern Australia. Archaeology in Oceania 23:1-16.

PÉREZ-PÉREZ A. 1996. Aborigines from Tierra del Fuego: human adaptation to a harsh environment. En Notes on populational significance of paleopatological conditions: health, illnes and death in the past, pp.107-122. Compilador Pérez-Pérez A., Fundación
Uriach 1838, Barcelona, España.

PIANA E. L. 1996. Informe sobre los restos óseos hallados en el establecimiento Los Yámanas. Policía Provincial de Tierra del Fuego por Expte. Judicial № 58/ $06 \mathrm{CU}$ 1ra. J , Distrito J udicial Sur.

PIANA E. L., M. VÁZQUEZ, M. ÁLVAREZ y N. RÚA 2002. El sitio Ajej: excavación de rescate en la costa del canal Beagle. En prensa en Actas del XIV Congreso Nacional de Arqueología Argentina, Rosario.

PRIETO A. y R. CÁRDENAS 2001. Ajuar de cueros en entierros de canoeros en el archipiélago de Tierra del Fuego. Anales del Instituto de la Patagonia 29: 183188. Punta Arenas, Chile.

SALEMME M. y M. E. MANSUR 2002. Informe de impacto al patrimonio cultural provincial, Ley provincial 370, por hallazgo producido en el predio del Aeroclub de Ushuaia. Para Dirección de Ciencia y Tecnología. Subsecretaría de Planeamiento y Desarrollo. Prov. de Tierra del Fuego, Argentina.

SANCHEZ ALBORNOZ N. 1958. Una penetración neolítica en Tierra del Fuego. En Cuadernos del Sur, Bahía Blan$\mathrm{ca}$, Argentina, $23 \mathrm{pp}$.

SAN ROMAN M. y F. MORELLO 2001. Canal Maule: nuevos antecedentes sobre prácticas funerarias en el Archipiélago Fueguino. Anales del Instituto de la Patagonia 29: 149-161. Punta Arenas, Chile.

SCHEUER L. y S. BLACK 2000. Developmental J uvenile Osteology. Academic Press.

SPENCER B. 1951. Spencer's last journey, being the journal of an expedition to Tierra del Fuego by the late Baldwin Spencer, with a memoir. Compilado por Marett R. R. y T. K. Penniman Balfour. Clarendon Press, Oxford, Inglaterra.

TESSONE A. 2003. Conductas mortuorias en el canal Beagle. Tesis de Licenciatura en Facultad de Filosofía y Letras, Universidad de Buenos Aires, Argentina.

TESSONE A., F. J. ZANGRANDO, S. VALENCIO y $\mathrm{H}$. PANARELLO 2003. Isótopos estables del carbono en restos óseos humanos de la región del Canal Beagle, Isla Grande de Tierra del Fuego. Revista Argentina de Antropología Biológica 5 (2): 33-43. Argentina.

UBELAKER D. 1989. Human Skeletal Remains, 3edición. Taraxacum Press, Washington D.C, Estados Unidos.

VAN DE MAELE M. 2000. Enterratorios Yámana: relato de las últimas memorias en Puerto Williams. Museos 24: 1-6, Chile.

VILA MITJA A. 2004. Proyectos etnoarqueológicos en Tierra del Fuego (Argentina). Bienes Culturales 3 : 193-200. Madrid, España.

VILA MITJA A., O. VICENTE, O. DE CASTRO, A. CASAS, J. ESTÉVEZ, J. A. BARCELÓ y L. MAMELI 2002. Informe de la campaña de excavaciones inserta en el proyecto "Sociedad y Ritual de los últimos cazadores-recolectores del canal Beagle (Tierra del Fuego, Argentina)(directora Dra. Asunción Vila Mitja)". Ministerio de Educación y Cultura de España.

ZANGRANDO A. F., M. DEL PAPA, C. NEGRO y M. J. ARREGUI 2004. Estudios tafonómicos y de procesos de modificación ósea postdepositacional en entierros humanos de la cuenca del lago Salitroso (NO de la Provincia de Santa Cruz). En Contra Viento y Marea. Arqueología de la Patagonia, pp. 375-386. Compiladores Civalero M. T., P. M. Fernandez y A. G. Guraieb. INAPL, Buenos Aires, Argentina. 